\title{
Проблемы формирования временной перспективы детей-сирот подросткового возраста (библиографический обзор)
}

\author{
Н. И. ФЕДОТОВА \\ (МОСКОВСКИЙ ГУМАНИТАРНЫЙ УНИВЕРСИТЕТ)
}

В данной статье представлен обзор имеющихся в отечественной науке исследований, посвященных проблеме формирования временной перспективы детей-сирот подросткового возраста.

Эта проблема рассматривается как с точки зрения индивидуальной биографии и жизненного пути личности (К. А. Абульханова-Славская, Е. И. Головаха, А. А. Кроник, С. Л. Рубинштейн и др.), субъективных представлений о времени (В. И. Ковалев, Л. Ю. Кублицкене и др.), так и с точки зрения психологического времени (В. Г. Асеев, Р. А. Ахмеров, Ж. Нюттен, И. А. Ральникова и др.). При этом продолжает оставаться значимой проблема психологического времени в подростковом возрасте, так как именно в этот период проявляется осознание себя и своей жизни во времени (И. А. Демина, Л. А. Регуш и др.).

В работах А. М. Прихожан, Н. Н. Толстых отмечается, что в ситуации утраты семьи, резкого изменения социальной действительности осуществление жизненных планов, самоопределение личности у подростков, воспитывающихся без семьи, сталкивается с реальными противоречиями между необходимостью и возможностью долговременного планирования ими своей жизни, а также приводит к отсутствию планов на будущее, нежеланию их строить. Для них характерны ситуативность желаний, слабая ориентированность на будущее, отсутствие временного плана собственных действий.

В результате многочисленных исследований было установлено, что столкновение личности с психотравмирующими событиями влечет за собой отсутствие желания планировать свое будущее и негативное отношение к нему. Во многих отечественных исследованиях высказывается идея формирования особого типа личности у ребенка, воспитывающегося в детском доме.

У воспитанников закрытых детских учреждений отсутствуют мотивы и представления, связанные с прошлым, наблюдается проекция травмирующих факторов в будущее. У них отмечается доминирование краткосрочных целей, «замыкание» на настоящем, неумение смотреть вперед и связывать актуальные события своего будущего с наиболее важными событиями прошлого, отсутствует реальное видение собственной жизни.

Ключевые слова: временная перспектива; дети-сироты; подростковый возраст; психология детства; психология сиротства

\section{ВВЕАЕНИЕ}

$\mathbf{R}$ озрастание темпов жизни требует от человека более осмысленного отноше-

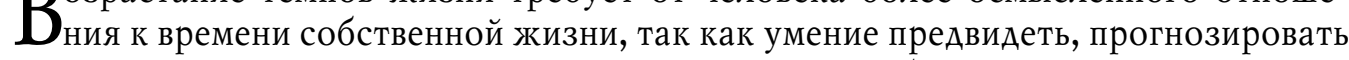
и строить жизненные планы влияет на жизненный выбор, организацию и осуществление деятельности. Одной из главных особенностей подросткового возраста является обращенность подростков в будущее.

Различные подходы к изучению временной перспективы представлены в работах К. А. Абульхановой-Славской, Р. А. Ахмерова, А. А. Кроника, Ж. Нюттена и др. Аанная проблема составляет часть более широкой психологической проблемы психологического времени и жизненного пути. 
Изучение конкретного жизненного пути, его специфических временных, биографических, событийных характеристик восходит еще к трудам А. Адлера, Ш. Бюлер, Т. Коттле и др. В отечественной психологии данным проблемам посвятили свои работы Б. Г. Ананьев, $\Lambda$. И. Божович, $\Lambda$. С. Выготский, А. Н. Аеонтьев, С. $\Lambda$. Рубинштейн и др. Специально исследовалась субъективная картина жизненного пути с позиции причинно-целевой концепции психологического времени (Р. А. Ахмеров, Е. И. Головаха, А. А. Кроник и др.), в контексте целостного жизненного пути (К. А. Абульханова-Славская, А. И. Анциферова, М. Р. Гинзбург, $\Lambda$. Ю. Кублицкене, С. $\Lambda$. Рубинштейн и др.).

$\mathrm{K}$ проблемам деформации субъективной картины жизненного пути в отечественной психологии были обращены многочисленные исследования О. С. Гурова, Е. А. Ипполитова, И. А. Ральникова, И. В. Шмыкова и др., в ходе которых установлено, что столкновение личности с психотравмирующими событиями влечет за собой отсутствие желания планировать свое будущее и негативное отношение к нему.

Образ будущего у юношей и девушек является сложным интегральным образованием, включающим в себя ценностные ориентации и первые жизненные планы, планируемые и ожидаемые события, усвоенные стереотипы социального поведения, элементы рефлексии и самооценки, установки и эмоциональное отношение к будущему (Божович,1996).

Само по себе наличие в подростковом возрасте представлений о будущем не является показателем успешной социализации. Показателем личной и социальной зрелости в подростковом возрасте может служить наличие сформированных представлений о дальнейшем жизненном пути (Кон, 2001).

Особенно важным становится исследование переживания времени у подростков, воспитывающихся вне семьи. Это объясняется тем, что созданные на сегодняшний день условия для нормального физического, умственного, психологического и социального развития детей-сирот не приводят к желаемому результату - к успешной их подготовке к самостоятельной жизни и бесконфликтной интеграции в общество.

В статье анализируются отечественные исследования представлений о временной перспективе в подростковом и раннем юношеском возрасте. Это связано с тем, что данный возраст представляет собой чрезвычайно важный период в становлении личности, связанный с осуществлением значимых выборов: профессии, системы ценностей и т. А. Наличие зрелых, сформированных представлений о будущем именно в этом возрасте становится необходимой предпосылкой дальнейшего развития личности. Важным является анализ работ, посвященных особенностям развития и формирования временной перспективы у подростков, воспитывающихся без семьи.

\section{ВРЕМЕННАЯ ПЕРСПЕКТИВА АЕТЕЙ-СИРОТ ПОАРОСТКОВОГО ВОЗРАСТА}

Подростковый возраст был и остается начальным и во многом определяющим для формирования временной перспективы как целостного образования, с одной стороны, и наиболее уязвимым психологически - с другой стороны. В связи с этим мы полагаем, что подростки нуждаются в повышенном внимании по вопро- 
су построения у них адекватной временной перспективы (Некрасова, 2000). Осознание подростками необходимости планирования жизненного пути предполагает помощь им в составлении жизненных планов, что включает выдвижение этапных целей, разработку путей их достижения и рефлексию смысла поставленных целей.

Психологические исследования свидетельствуют о том, что общее физическое и психическое развитие детей-сирот отличается от развития ровесников, растущих в семьях, и, вступая в самостоятельную жизнь, выпускники учреждений для детей-сирот часто не готовы к лишению привычной опеки и испытывают трудности в формировании своей временной перспективы (К. А. Абульханова-Славская, И. В. Аубровина, А. А. Запорожец, М. И. Аисина, В. С. Мухина, В. Н. Ослон, А. М. Прихожан, Н. К. Радина, А. Г. Рузская, Н. Н. Толстых и Ар.). На некоторых из этих исследований хотелось бы остановиться более подробно.

Аля оценки сформированности представлений человека о своем будущем в психологических исследованиях применяют разные критерии. Например, К. А. Абульханова-Славская называет следующие:

1) продолжительность и дифференцированность временной перспективы: представленность ближней, средней и дальней перспективы;

2) реалистичность будущего среднего масштаба;

3) сочетание конкретности и перспективности;

4) согласованность жизненных планов, целей и ценностей;

5) активность и самостоятельность при формировании жизненной перспективы;

6) оптимистичность представлений о будущем (Абульханова-Славская, 1991: 112).

В ситуации утраты семьи, резкого изменения социальной действительности осуществление жизненных планов, самоопределение личности у подростков, воспитывающихся без родителей, сталкивается с реальными противоречиями между необходимостью и возможностью долговременного планирования ими своей жизни, а также приводит к отсутствию планов на будущее, нежеланию их строить (Ральникова, 2002; Прихожан, Толстых, 2007). Аля подростков-сирот характерны ситуативность желаний, слабая ориентированность на будущее, отсутствие временного плана собственных действий (Кроник, Ахмеров, 2003).

В связи с актуальностью поиска оптимальных путей подготовки детей-сирот к жизни, формирования у них ориентаций на будущее рассмотрим особенности личности детей и подростков, воспитывающихся в условиях материнской депривации.

В психологии принято выделять следующие виды депривации: двигательная, сенсорная, материнская (семейная) и социальная. Чехословацкие ученые Й. Аангмейер и 3. Матейчик обнаружили, что в числе последствий материнской депривации является неразвитость временной перспективы будущего у детей, растущих без родителей (Иангмейер, Матейчик, 1991). По их мнению, становлению перспективы будущего у детей-сирот препятствует отсутствие четких представлений о своем прошлом. Отечественные ученые большое значение придавали исследованию отношений матери и ребенка, но не считали их биологически обусловленными, находя более целесообразным политропность малыша - наличие у него многочисленных и прочных связей с окружающими взрослыми. Так, в работах, посвя- 
щенных особенностям личности детей, воспитывающихся вне семьи, показано, что в условиях закрытого детского учреждения чаще всего формируется личность с низким уровнем ответственности по отношению к собственному времени жизни, что обусловлено эмоциональным неблагополучием детей и их тревогой по поводу прошлого, настоящего и будущего (Аубровина, Рузская, 1990; Прихожан, Толстых, 2007 и др.).

Так, было проведено исследование временной перспективы школьников и воспитанников школы-интерната (Аубровина, Рузская, 1990). Подростки, воспитывающиеся в интернате, часто не указывают конкретную профессию в отличие от школьников, проживающих в семьях, которые больше ориентированы на содержательный аспект выбираемой профессии. Показано, что у подростков, воспитывающихся в интернате, часто отсутствуют четкие представления о прошлом, что, по мнению авторов, может препятствовать формированию их ориентации на будущее. Было выявлено, что часть детей считают, что они вообще никогда не были маленькими. Ориентация детей-сирот на настоящее время выражена в преобладании в их жизни сиюминутных потребностей. Неумение мечтать, фантазировать, стремиться к чему-либо, по мнению авторов, также не способствует у детей-сирот развитию способности строить планы на будущее.

Психологические исследования Н. $\Lambda$. Белопольской и ее коллег показывают, что при неблагоприятном развитии личности в подростковый период (у злоупотребляющих алкоголем, с признаками возникающих наркоманической, токсикоманической зависимостей, при подростково-юношеской депрессии, в случае девиантного поведения и т. п.) фиксируется значительное сужение временной перспективы, тенденция жить сегодняшним днем, не заботясь о завтрашнем или даже вообще как бы игнорируя течение времени (Самосознание проблемных подростков, 2007). Также, по результатам их исследований, подростки с неустойчивым поведением, целеполаганием и мотивацией демонстрируют наличие равнодушного отношения к будущему, несформированность представлений и нежелание думать о нем. У них нет профессиональных или иных планов на будущее, они сосредоточены на настоящем, ценностная направленность - на получение удовольствия. Следствием отсутствия сформированной временной перспективы в подростковом возрасте может быть возникновение чувства безнадежности, одиночества. Также отсутствие перспективы будущего может быть причиной суицидального поведения у подростков.

А. М. Прихожан и Н. Н. Толстых, изучая особенности мотивации детей-сирот, использовали методику известного бельгийского психолога Ж. Нюттена «Метод мотивационной индукции» (Прихожан, Толстых, 2007; Нюттен, 2004). Сравнив ответы учащихся 6-х, 7-х, 8-х классов школы-интерната и обычной школы, авторы выявили, что у первых во всех возрастных группах по сравнению с учащимися второй группы преобладают мотивы, связанные с сегодняшним днем и ближайшим будущим («подготовиться к контрольной», «убрать класс», «дочитать книгу», «пойти на секцию» и т. п.). Таким образом, временная перспектива у них ограничена ближайшим будущим (день-два).

Преобладающие в школе-интернате высказывания, связанные со спортом и отдыхом, хоть и выходят, как правило, за пределы одного-двух дней и связаны с ближайшими неделями, месяцами или предстоящими каникулами, вместе с тем также 
относятся к сравнительно близкому будущему. Исследователи обращают внимание на то, что учащиеся массовой школы заметно отличаются от воспитанников интерната тем, что их мечты, планы, желания в значительно большей степени связаны с будущим, причем подчас довольно отдаленным: они часто говорят о своей предполагаемой профессии, о желании поступить в институт, о том, каким человеком хотят стать. Исследователи также отмечают, что детям-сиротам свойственна низкая мотивация относительно учебы и профессионального самоопределения, что не характерно для детей, воспитывающихся в семьях. Воспитанников детского дома профессия интересует исключительно как способ заработать деньги, но не как способ самореализации.

Изучая временные представления подростков, воспитывающихся в семье и в детском доме, Н. $\Lambda$. Белопольская и ее коллеги установили, что отношение к будущему у подростков из семей оптимистичное, на вопросы этого параметра отвечают все (Самосознание проблемных подростков, 2007). Прошлое вспоминается в радужных тонах. Планы на будущее не конкретны, но дети полны свершений, ориентированы на достижения. Страхи о будущем обобщенные: «Боюсь трудностей, связанных с взрослой жизнью», «...что не сложится карьера». Аругая картина у подростков из детских домов. Многие из них вообще не отвечают на вопросы о будущем. Отношение к нему пессимистичное, часто на вопрос о будущем отвечают: «Я умру». Прошлое вспоминают в черных, негативных тонах. Страхи будущего конкретны: «Не поступлю в институт», «Не найду работу». По неоконченному предложению: «Я стремлюсь...» результаты также весьма различаются. Большинство сирот говорят о ближайшей перспективе, их суждения конкретны: «поступить в училище», «окончить школу». Стремления подростков из семей обобщенные, лаконичные, ориентированы на далекую перспективу, идеал: «стремлюсь к счастью», «...карьере», «...быть образованным, уважаемым». В целом отношение к будущему положительное, они готовы идти вперед, у них есть идеал. Полученные данные говорят о том, что для воспитанников интерната «будущее» является фрустрированным, т. е. вызывает чувство опасения и даже страха из-за непонимания.

Представления о собственном возрасте также имеют различия у детей указанных групп. Более половины опрошенных детей-сирот оценивают его неадекватно: $62 \%$ считают себя в настоящий момент младше по возрасту, 27\% считают себя старше, и только 11\% подростков соотносят себя со своим психологическим временем (там же: 253-254). Наиболее значимым для себя большинство детей считают свое прошлое (54\%), 12\% - настоящее, $34 \%$ ориентированы на будущее. Авторы предполагают, что это может свидетельствовать о преобладании инфантильности над стремлением к взрослению и чувством реальности у воспитанников детских домов, интернатов.

Анализ ответов подростков на вопросы о событиях собственной жизни показал исследователям наиболее типичные мнения детей, воспитывающихся в учреждениях интернатного типа. В подавляющем большинстве подростки указывали на психические травмы, связанные со стрессовыми ситуациями в семье, травмирующие факторы сохраняют свое воздействие в настоящем и проецируются в будущее. У подростков были выявлены тревожность, неуверенность в собственных силах и в своей ценности, вследствие этого у них наблюдались притязания на признание (там же: 257-258). 
Таким образом, можно выделить ряд наиболее острых социальных, социальнопедагогических и психологических проблем, затрудняющих процесс формирования адекватной временной перспективы у детей-сирот: ситуативность желаний, слабая ориентированность на будущее, отсутствие временного плана собственных действий, отсутствие четких представлений о своем прошлом, ориентация детейсирот на настоящее время выражена в преобладании в их жизни сиюминутных потребностей, неумении мечтать и фантазировать, в отсутствии у них профессиональных или иных планов на будущее, направленность - на получение удовольствия, «будущее» часто является фрустрированным для детей-сирот, т. е. вызывает чувство опасения и даже страха из-за непонимания.

\section{ЗАКАЮЧЕНИЕ}

Таким образом, обзор исследований отечественных психологов, педагогов, которые проводились с начала 1990-х годов по настоящее время, показывает, что существуют два основных подхода к изучению временной перспективы:

- теория жизненного пути и психологическая концепция исследования личности в качестве субъекта жизни (Б. Г. Ананьев, К. А. Абульханова-Славская, М. Р. Гинзбург, В. И. Ковалев, Т. Н. Березина, А. Н. Аеонтьев, С. А. Рубинштейн);

- особенности восприятия времени с позиции причинно-целевой концепции психологического времени (Е. И. Головаха, А. А. Кроник, Р. А. Ахмеров и др.).

В результате многочисленных исследований было установлено, что столкновение личности с психотравмирующими событиями влечет за собой отсутствие желания планировать свое будущее и негативное отношение к нему. Во многих отечественных исследованиях высказывается идея формирования особого типа личности у ребенка, воспитывающегося в детском доме.

У воспитанников закрытых детских учреждений отсутствуют мотивы и представления, связанные с прошлым, наблюдается проекция травмирующих факторов в будущее. У них отмечается доминирование краткосрочных целей, «замыкание» на настоящем, неумение смотреть вперед и связывать актуальные события своего будущего с наиболее важными событиями прошлого, отсутствует реальное видение собственной жизни. По данным многих авторов, в ситуации утраты семьи, резкого изменения социальной действительности дети-сироты сталкиваются с реальными противоречиями между необходимостью и возможностью долговременного планирования ими своей жизни. Это приводит к искажению, сокращению жизненной перспективы, отсутствию планов на будущее, нежеланию их строить.

\section{СПИСОК АИТЕРАТУРЫ}

Абульханова-Славская, К. А. (1991) Стратегии жизни. М. : Мысль. 302 с.

Божович, $\Lambda$. И. (1996) Проблемы формирования личности: Избранные психологические труды / под ред. А. И. Фельдштейна. М. : Институт практической психологии. 352 с.

Аубровина, И. В., Рузская, А. Г. (1990) Психическое развитие воспитанников детского дома. М. : Просвещение. 264 с.

Кон, И. С. (2001) Жизненный путь как предмет междисциплинарного исследования // Психология личности в трудах отечественных психологов / сост. и общ. ред. $\Lambda$. В. Куликова. СПб. : Питер. 384 с. С. 269-278. 
Кроник, А. А., Ахмеров, Р. А. (2003) Каузометрия. Методы самопознания, психодиагностики и психотерапии в психологии жизненного пути. М. : Смысл. 306 с.

Мангмейер, Й., Матейчик, 3. (1991) Типы депривационной личности ребенка в учреждении // Аишенные родительского попечительства : хрестоматия / ред. В. С. Мухина. М. : Просвещение. 223 с. С. 205-213.

Некрасова, Е. В. (2000) Исследование проблемы времени в психологии. Барнаул : Иза-во БГПУ. 124 с.

Нюттен, Ж. (2004) Мотивация, действие и перспектива будущего. М. : Смысл. 608 с.

Прихожан, А. М., Толстых Н. Н. (2007) Психология сиротства : учеб. пособие для вузов. СПб. : Питер. 400 с.

Ральникова, И. А. (2002) Жизненные перспективы личности: психологический контекст. Барнаул : ИзА-во Алт. ун-та. 152 с.

Самосознание проблемных подростков (2007) / Н. А. Белопольская, С. Р. Иванова, Е. В. Свистунова, Е. М. Шафирова. М. : Изд-во Института психологии РАН. 332 с.

Аата поступления: 20.05.2016 г.

\section{SHAPING THE TIME PERSPECTIVE IN TEENAGE ORPHANS \\ ( A BIBLIOGRAPHIC SURVEY) \\ N. I. FEDOTOVA \\ (MOSCOW UNIVERSITY FOR THE HUMANITIES)}

The article provides a survey of Russian studies in the formation of the time perspectives in orphaned children during their teenage years.

This problem has been approached biographically (K. A. Abul'khanova-Slavskaia, E. I. Golovakha, A. A. Kronik, S. L. Rubinshtein, etc.), as well as from the standpoint of subjective understanding of time (V. Yu. Kovalev, L. Yu. Kublitskene, etc.) or of psychological time (V. G. Aseev, R. A. Akhmerov, J. Nutten, I. A. Ral'nikova, etc.). The issue of psychological time in teenagers remains significant, as adolescence is the age when individuals recognize how their lives are played out in time (I. A. Demina, L. A. Regush, etc.)

A. M. Prikhozhan, N. N. Tolstykh and other researchers have noted that the loss of family and a sharp change in social environment makes self-identification in teenage orphans face the serious conflict between the need for life planning and their inability to do so. It also makes teenage orphans unwilling to set plans for their own future. They typically feature situational desires, low commitment to self-development and an inability to schedule their plans for future.

As a number of studies have shown, undergoing a psychological trauma leads to the negative attitude to one's own future and to a lack of desire to plan it. Some researchers suggest that growing up in an orphanage helps shape a specific type of personality.

Those growing up in sheltered institutions often lack motives and images of the past and ten to project traumatic experience onto the future. They are motivated by short-term goals, excessively fixated on the present, unable to look forward and link the topical events of the future to significant events in the past. In short, they do not have a clear vision of their own life, which leads to a distorted view of their life perspective.

Keywords: time perspective; orphaned children; adolescence; psychology of childhood; psychology of orphanhood

\section{REFERENCES}

Abul'khanova-Slavskaia, K. A. (1991) Strategii zbizni. Moscow, Mysl'. 302 p. (In Russ.).

Bozhovich, L. I. (1996) Problemy formirovaniia licbnosti: Izbrannye psikbologicheskie trudy, ed. D. I. Fel'dshtein. Moscow, Institut prakticheskoi psikhologii. 352 p. (In Russ.). 
Dubrovina, I. V. and Ruzskaia, A. G. (1990) Psikbicheskoe razvitie vospitannikov detskogo doma. Moscow, Prosveshchenie. 264 p. (In Russ.).

Kon, I. S. (2001) Zhiznennyi put' kak predmet mezhdistsiplinarnogo issledovaniia. In: Psikbologiia lichnosti v trudakh otechestvennykh psikhologov, comp. and ed. L. V. Kulikov. St. Petersburg, Piter. 384 p. Pp. 269-278. (In Russ.).

Kronik, A. A. and Akhmerov, R. A. (2003) Kauzometriia. Metody samopoznaniia, psikbodiagnostiki i psikhoterapii v psikhologii zhiznennogo puti. Moscow, Smysl. 306 p. (In Russ.).

Langmeier, J. and Mateichik, Z. (1991) Tipy deprivatsionnoi lichnosti rebenka v uchrezhdenii. In: Lishennye roditel'skogo popechitel'stva: khrestomatiia, ed. V. S. Mukhina. Moscow, Prosveshchenie. 223 p. Pp. 205-213. (In Russ.).

Nekrasova, E. V. (2000) Issledovanie problemy vremeni v psikhologii. Barnaul, Izd-vo BGPU. 124 p. (In Russ.).

Nutten, J. (2004) Motivatsiia, deistvie i perspektiva budushchego. Moscow, Smysl. 608 p. (In Russ.).

Prikhozhan, A. M. and Tolstykh N. N. (2007) Psikhologiia sirotstva: uchebnoie posobie dlia vuzov. St. Petersburg, Piter. 400 p. (In Russ.).

Ral'nikova, I. A. (2002) Zhiznennye perspektivy lichnosti: psikbologicheskii kontekst. Barnaul, Izd-vo Altaiskogo un-ta. 152 p. (In Russ.).

Samosoznanie problemnykb podrostkov (2007), ed. N. L. Belopol'skaia, S. R. Ivanova, E. V. Svistunova and E. M. Shafirova. Moscow, Izd-vo Instituta psikhologii RAN. 332 p. (In Russ.).

Submission date: 20.05.2016.

Федотова Наталья Игоревна - кандидат психологических наук, доцент кафедры педагогики и психологии высшей школы Московского гуманитарного университета. Адрес: 111395, Россия, г. Москва, ул. Юности д. 5 . Тел.: +7 (499) 374-74-59. Эл. адрес: fedotova1973@mail.ru

Fedotova Natalya Igorevna, Candidate of Psychology, Associate Professor, Department of Pedagogy and Psychology of Higher School, Moscow University for the Humanities. Postal address: 5 Yunosti St., 111395, Moscow, Russian Federation. Tel.: +7 (499) 374-74-59. E-mail: fedotova1973@mail.ru 